Article

\title{
The Small GTPase FgRab1 Plays Indispensable Roles in the Vegetative Growth, Vesicle Fusion, Autophagy and Pathogenicity of Fusarium graminearum
}

\author{
Yanping Yuan ${ }^{1} \mathbb{D}$, Meiru Zhang ${ }^{1}$, Jingjing Li $^{1}$, Chengdong Yang ${ }^{1}$, Yakubu Saddeeq Abubakar ${ }^{1,2} \mathbb{D}$, Xin Chen ${ }^{3}$,
} Wenhui Zheng ${ }^{3}$, Zonghua Wang ${ }^{1,4}$, Huawei Zheng ${ }^{4, *}$ and Jie Zhou ${ }^{1, *}$ D

Citation: Yuan, Y.; Zhang, M.; Li, J.; Yang, C.; Abubakar, Y.S.; Chen, X.; Zheng, W.; Wang, Z.; Zheng, H.; Zhou, J. The Small GTPase FgRab1 Plays Indispensable Roles in the Vegetative Growth, Vesicle Fusion, Autophagy and Pathogenicity of Fusarium graminearum. Int. J. Mol. Sci. 2022, 23, 895. https://doi.org/ $10.3390 /$ ijms23020895

Academic Editor: Raffaella Maria Balestrini

Received: 20 December 2021

Accepted: 11 January 2022

Published: 14 January 2022

Publisher's Note: MDPI stays neutral with regard to jurisdictional claims in published maps and institutional affiliations.

Copyright: (C) 2022 by the authors. Licensee MDPI, Basel, Switzerland. This article is an open access article distributed under the terms and conditions of the Creative Commons Attribution (CC BY) license (https:// creativecommons.org/licenses/by/ $4.0 /)$.
1 Fujian Universities Key Laboratory for Plant-Microbe Interaction, College of Life Sciences, Fujian Agriculture and Forestry University, Fuzhou 350002, China; yyuan97@163.com (Y.Y.); zmr17629780871@163.com (M.Z.); 13414927525@163.com (J.L.); Chengdy@hainanu.edu.cn (C.Y.); ay.saddeeq@yahoo.com (Y.S.A.); wangzh@mju.edu.cn (Z.W.)

2 Department of Biochemistry, Faculty of Life Sciences, Ahmadu Bello University, Zaria 810211, Nigeria

3 State Key Laboratory of Ecological Pest Control for Fujian and Taiwan Crops, College of Plant Protection, Fujian Agriculture and Forestry University, Fuzhou 350002, China; danhinm1996@outlook.com (X.C.); wenhuiz@fafu.edu.cn (W.Z.)

4 Marine and Agricultural Biotechnology Laboratory, Institute of Oceanography, College of Geography and Oceanography, Minjiang University, Fuzhou 350108, China

* Correspondence: zhw@mju.edu.cn (H.Z.); jiezhou@fafu.edu.cn (J.Z.); Tel.: +86-15880036549 (H.Z.); $+86-13860626041$ (J.Z.)

\begin{abstract}
Rab GTPases are key regulators of membrane and intracellular vesicle transports. However, the biological functions of FgRab1 are still unclear in the devastating wheat pathogen Fusarium graminearum. In this study, we generated constitutively active (CA) and dominant-negative (DN) forms of $F g R A B 1$ from the wild-type $\mathrm{PH}-1$ background for functional analyses. Phenotypic analyses of these mutants showed that FgRab1 is important for vegetative growth, cell wall integrity and hyphal branching. Compared to the PH-1 strain, the number of spores produced by the Fgrab1DN strain was significantly reduced, with obviously abnormal conidial morphology. The number of septa in the conidia of the Fgrab1DN mutant was fewer than that observed in the PH-1 conidia. Fgrab1DN was dramatically reduced in its ability to cause Fusarium head blight symptoms on wheat heads. GFP-FgRab1 was observed to partly localize to the Golgi apparatus, endoplasmic reticulum and Spitzenkörper. Furthermore, we found that FgRab1 inactivation blocks not only the transport of the v-SNARE protein FgSnc1 from the Golgi to the plasma membrane but also the fusion of endocytic vesicles with their target membranes and general autophagy. In summary, our results indicate that FgRab1 plays vital roles in vegetative growth, conidiogenesis, pathogenicity, autophagy, vesicle fusion and trafficking in F. graminearum.
\end{abstract}

Keywords: Fusarium graminearum; FgRab1; constitutively active; dominant negative; vesicle transport; autophagy; pathogenicity

\section{Introduction}

Ras related in brain (Rab) GTPases make up the largest group of the small GTPase family (called Ypt proteins in yeast) and function as molecular switches in the regulation of intracellular membrane trafficking in all eukaryotic cells [1-4]. Rab GTPases alternate between active GTP-bound and inactive GDP-bound states, which are facilitated by guanine nucleotide exchange factors (GEFs) and GTPase-activating proteins (GAPs), respectively [4]. Rab GTPases have a conserved GTP/GDP core and hydrolysis domain with highly conserved motifs, such as G1 (Walker A/P-loop; GxxxxG K[S/T]), which is implicated in the binding of the $\beta$ - and $\gamma$-phosphate groups of nucleotides [5,6]. In fungi, the number of 
Ypt/Rab protein families is stable from 7 to 12 [4,7,8], of which Rab5/Ypt5, Rab7/Ypt7 and Rab8/Sec4 are well studied.

Rab GTPases have been systematically investigated in the filamentous fungus Aspergillus nidulans. The members of this protein family have been shown to be involved in multi-fungal intracellular trafficking processes, including exocytosis and endocytosis, and the Spitzenkörper of A. nidulans has been shown to harbor four Rab proteins, namely, Rab11, Sec4/Rab8, Rab6 and Rab1 [1]. In addition to those in A. nidulans, the Rab GTPases in other fungi, notably, Ustilago maydis, Magnaporthe oryzae, Neurospora crassa and F. graminearum, have also been well investigated [1,9].

Rab GTPases (including Rab8/Sec4, Rab7/Ypt7 and Rab5) have been well studied in the last ten years, especially in plant pathogenic fungi. In the hemibiotrophic pathogen Colletotrichum orbiculare, Sec4 was shown to localize to the necks of biotrophic primary hyphae, adjacent to the interface, and the deletion of SEC4 reduced the virulence and disrupted effector delivery to the ring interface [10]. In $U$. maydis, the deletion of Rab5a reduced effector transcription and secretion, preventing the fungus from effectively colonizing plant tissues [11]. BcSAS1, the Rab8/SEC4-like gene, plays an important role in the development, protein secretion and virulence of Botrytis cinerea [12]. In Fusarium verticillioides, FvSec4 is necessary for fumonisin B1 biosynthesis and virulence [13]. In the rice blast fungus M. oryzae, Rab5A and Rab5B are essential for the development and pathogenicity of the fungus, but they have distinct biochemical and functional properties [14,15]; MoRab7/Ypt7 is required for membrane fusion during autophagy and pathogenicity [16], and it recruits the retromer cargo-sorting complex to the endosome [17]. Rab8/Sec4 is involved in vegetative growth and pathogenicity by regulating extracellular protein secretion [18]. In the plant fungal pathogen Colletotrichum lindemuthianum, CLPT1 (Sec4) is required for protein secretion and pathogenesis [19].

The above studies mainly focus on Rab5, Rab7/Ypt7 and Rab8/Sec4. However, the roles of Rab1 (Ypt1) in plant pathogenic fungi are still unclear. In yeast, YPT1 is an essential gene $[20,21]$, in which Asn121-IIe substitution within the gene product had a dominant lethal phenotype [22]. Ypt1 is involved in microtubule organization, where it functions in the secretion pathway, and it is required for transport to and through the Golgi apparatus [23]. In Schizosaccharomyces pombe, Ypt1 is essential for cell growth [24]. The overexpression of a dominant-negative allele of YPT1 inhibits growth and aspartyl protease secretion in the pathogenic yeast Candida albicans [25]. In mammalian cells, Rab1 is required for the fusion of carrier vesicles, thereby mediating endoplasmic reticulumto-Golgi transport [26]. However, the roles of Rab1/Ypt1 in plant pathogenic fungi are still unknown.

F. graminearum is a filamentous ascomycete and the causal agent of Fusarium head blight (FHB) in wheat worldwide [27-30]. F. graminearum infects wheat spikelets and colonizes the entire wheat head by growing through the rachis node at the bottom of each spikelet [31]. In addition, during the infection of F. graminearum on wheat florets, it forms specialized infection structures, such as lobate appressoria and infection cushions [32]. In addition to wheat, F. graminearum also infects maize, barley and other small grains [33-36]. F. graminearum infections not only result in severe yield losses but also contaminate the grains with various mycotoxins, imposing serious potential impacts on human and animal health [37]. In F. graminearum, Rab GTPases are essential for membrane traffickingdependent growth, DON production and pathogenicity [9]; FgRab51 and FgRab52 regulate early endocytosis; FgRab7 regulates late endocytosis and vacuolar fusion; and FgRab8 and FgRab11 are required for polarized growth and secretion. Furthermore, FgVps9, FgSec2A and FgMon1 were identified as the guanine nucleotide exchange factors (GEFs) of FgRab5, FgRab8 and FgRab7, respectively [38-40]. FgGyp1 and FgMsb3 were demonstrated to act as the GTPase-activating proteins (GAPs) for FgRab1 and FgRab8, respectively [41,42], and they are both required for the SNARE protein FgSnc1-mediated fusion of vesicles with the plasma membrane. 
Considering the fact that Rab1/Ypt1 is an essential gene, particularly in yeast, this study focused on investigating the functions of FgRab1 in the development and pathogenesis of F. graminearum. We found that the overexpression of a dominant-negative form of FgRab1 inhibits vegetative growth, conidiation, cell wall integrity, pathogenicity, autophagy and the transport of v-SNARE FgSnc1 from the Golgi to the plasma membrane in F. graminearum. Furthermore, FgRab1 localizes to the Golgi apparatus, endoplasmic reticulum and Spitzenkörper.

\section{Results}

\subsection{Identification of FgRab1 in F. graminearum}

We have previously identified FgRAB1 (FGSG_10873) in the F. graminearum genome using the NCBI database (https: / / www.ncbi.nlm.nih.gov / , accessed on 13 January 2022) [9]. In the present study, we obtained the amino acid sequence of FgRab1 and its homolog proteins in 15 different species, and we used MEGA5 software to construct the phylogenetic tree of the Rab1 protein. We found that the Rab1 proteins are relatively conserved in most species, and FgRab1 is closest to Fusarium oxysporum in terms of evolutionary relationship (Figure 1A).

A

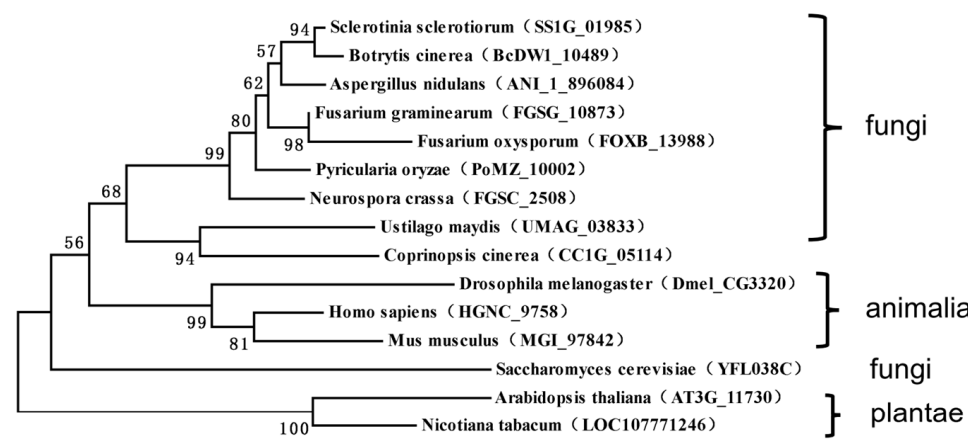

B
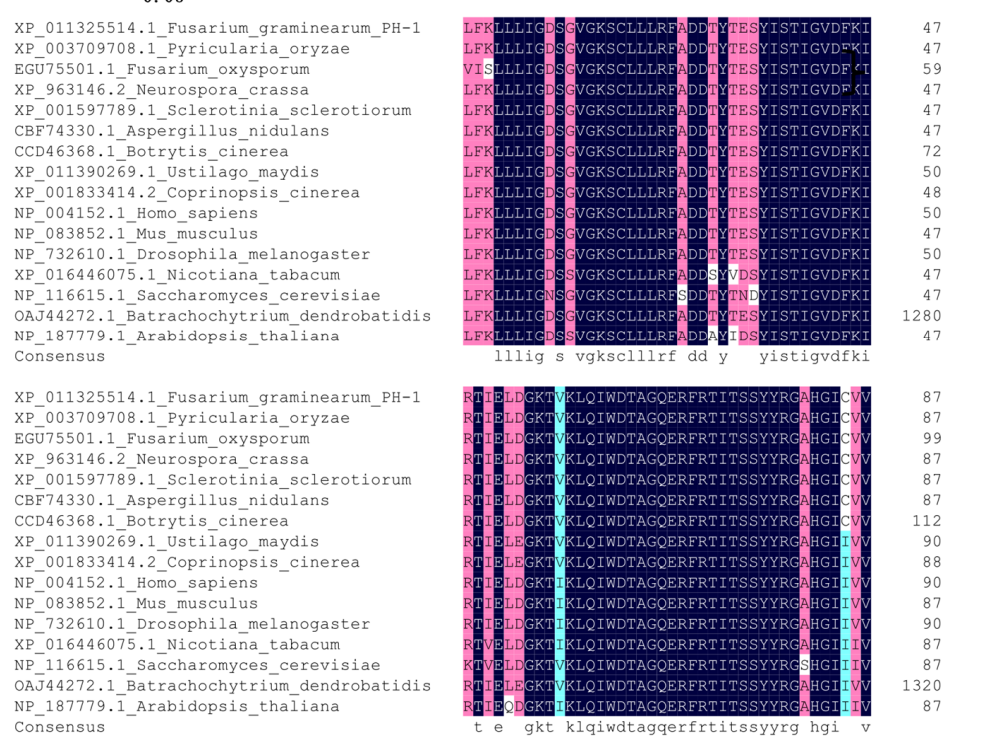

Figure 1. Bioinformatics analysis of Rab1 orthologs. (A) Phylogenetic analysis of Rab1 homologs in different species. (B) Multiple sequence alignment of Rab1 homologs.

Previous studies have shown that many Rab proteins are characterized by the presence of five specifically conserved domains, namely, IGVDF (RabF1), KLQIW (RabF2), RFRSIT (RabF3), YYRGA (RabF4) and LVYDIT (RabF5) [43]. The C-termini of these proteins may have the membrane positioning signal motif XXXCC, XXCCX, XCCXX, CCXXX or XXCXC (where $X$ is any amino acid), which can be prenylated to guide the Rab protein to anchor the 
target membrane [43-45]. The amino acid sequences of Rab1 proteins from 15 species were compared using DNAMAN software, and the sequence alignment results suggest that most of the Rab1 proteins have the above conserved domains (Figure 1B). Furthermore, previous studies revealed that Rab proteins generally possess GTP- and GDP-binding sites. Herein, our amino acid sequence comparison of the Rab1 proteins from 15 species showed that the GTP- and GDP-binding sites were very conservative in different species (Figure 1B).

\subsection{FgRab1 Is Critical for Vegetative Growth and Is Involved in the Maintenance of Cell Wall Integrity of F. graminearum}

A previous study indicated that the deletion of Ypt1 (Rab1 homolog) leads to death in S. cerevisiae [22]. We therefore intended to delete FgRab1 for its functional analyses. Similar to the above observation in yeast, the Fgrab1 mutant could not be obtained after several screenings, suggesting that the deletion of the protein is lethal to the fungus. As such, we used the point mutation strategy to modify the active site of the FgRab1 protein and successfully constructed Fgrab1CA (constitutively active, Q67L) (Figure S1A) and Fgrab1DN (dominant-negative, S22N) (Figure S1B) strains to analyze the gene function. We found that the growth of the Fgrab1DN strain was reduced by approximately $77 \%$ compared to the wild-type PH-1 strain, while the mycelial growth of the Fgrab1CA strain was only slightly reduced (Figure 2A). Moreover, mycelial branching was observed to increase in Fgrab1DN (Figure 2B), suggesting perturbation of the fungal polarity. To gain further insight into the effects of this mutation, the hyphae of the wild-type PH-1, Fgrab1CA and Fgrab1DN strains were stained with the fluorescent dye FM4-64 and observed under a confocal microscope. As shown in Figure 2C, the results showed an increase in the Fgrab1DN hyphal cell wall thickness compared to that of the wild type. However, the cell wall thickness of the Fgrab1CA strain was not affected. Taken together, these results indicate that FgRab1 is important for mycelial morphology and the polarized growth of F. graminearum.

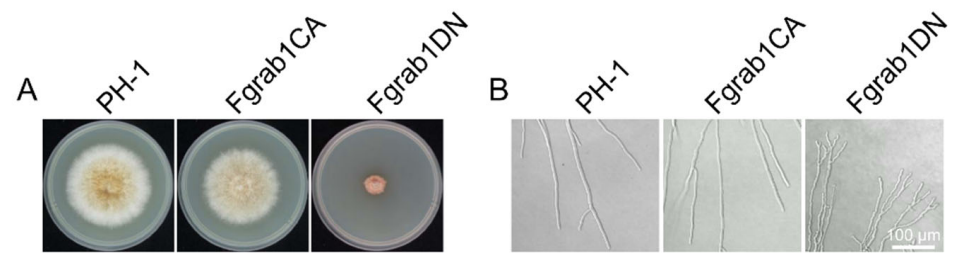

C

PH-1

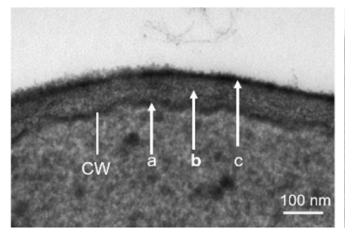

Fgrab1CA

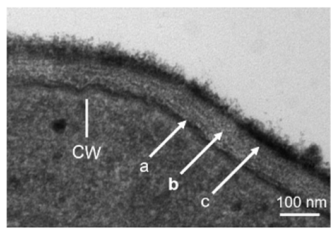

Fgrab1DN

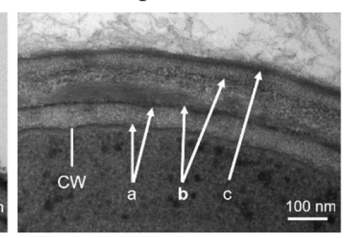

Figure 2. FgRab1 is important for vegetative growth and growth polarity in F. graminearum. (A) Colony morphology of the wild-type PH-1, Fgrab1CA and Fgrab1DN strains. (B) Mycelial morphology of PH-1, Fgrab1CA and Fgrab1DN. Hyperbranching was observed in the Fgrab1DN strain. (C) Fgrab1DN displays a thicker cell wall compared to wild-type PH-1. CW: cell wall. Arrows mark the different layers: a. internal electron-dense layer, b. middle electron-dense layer, c. external electron-dense layer.

Consistent with the above results, we observed during protoplast preparation of the various strains that the enzymatic cell wall degradation of the Fgrab1DN strain was very difficult to achieve. Two hours after treatment with the cell wall-degrading enzymes, most of the Fgrab1DN samples were still in their hyphal forms, and the protoplasts produced were significantly reduced compared to those obtained from the other strains (Figure S2). This supports the notion that the perturbation of FgRab1 function affects cell wall integrity in F. graminearum. 
2.3. FgRab1 Is Involved in Regulating Conidiogenesis but Not Sexual Reproduction in F. graminearum

To investigate the potential roles of FgRab1 in conidiogenesis, we cultivated wild-type PH-1, Fgrab1CA and Fgrab1DN in CMC media for 3 days to induce conidiation. We observed that the number of conidia produced by the Fgrab1DN strain was significantly decreased compared to PH-1 (Figure 3B). We further analyzed the distribution of the number of septa in each conidium and found that the number of septa was also significantly reduced. The number of septa in Fgrab1DN mainly ranged from zero to three, while that in the wild-type PH-1 conidia mainly concentrated around three (Figure 3C). These results suggest that FgRab1 is involved in conidia formation in F. graminearum.

A

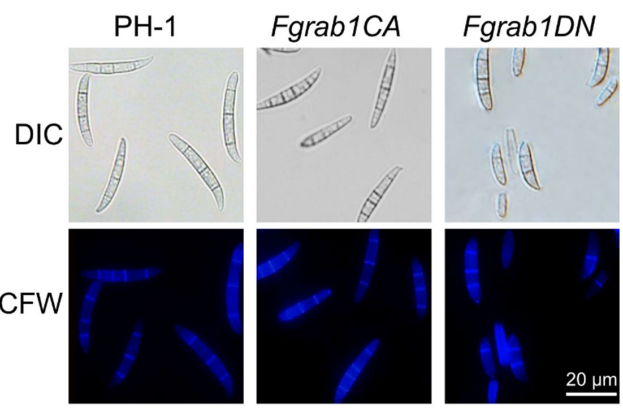

B

C
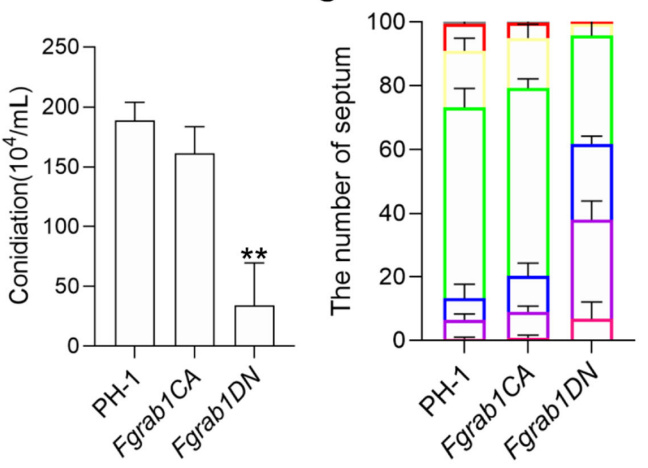

$\square \quad 6$
$\square \quad 5$
4
$\square \quad 3$
$\square \quad 2$
$\square \quad 1$
$\square \quad 0$

D

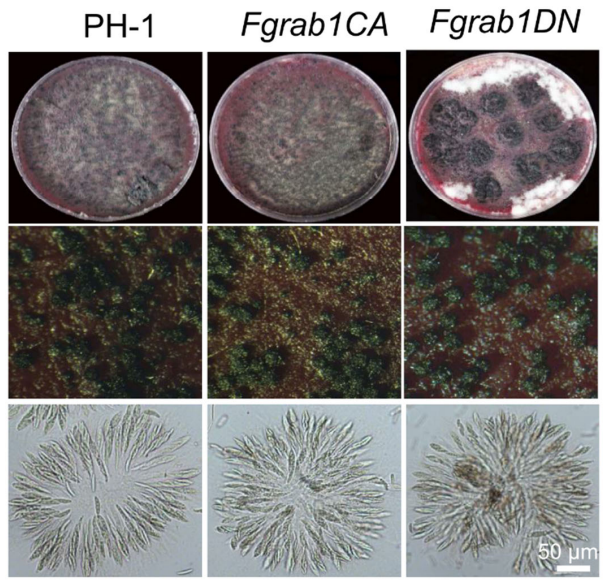

Figure 3. FgRab1 inactivation perturbs conidiation but not sexual reproduction in F. graminearum. (A) Conidial morphology of the wild-type PH-1, Fgrab1CA and Fgrab1DN strains, bar $=20 \mu \mathrm{m}$. (B) Conidia formation by the wild-type PH-1, Fgrab1CA and Fgrab1DN strains. Error bars represent SD from three replicates, and two-tailed Student's $t$-test was used for paired comparison of the conidiation between PH-1 vs. Fgrab1CA and Fgrab1DN strains ${ }^{* *}, p<0.01$ ). (C) The number of conidia septa of the indicated strains. Error bars represent SD from three replicates, which was used for paired comparison of the number of conidial septum between PH-1 vs. Fgrab1CA and Fgrab1DN. (D) Perithecia and ascospore formation by the indicated strains, bar $=50 \mu \mathrm{m}$. 
To determine whether FgRab1 is involved in sexual reproduction, we inoculated the wild-type PH-1, Fgrab1CA and Fgrab1DN strains on carrot media to induce sexual reproduction. We found that both Fgrab1CA and Fgrab1DN strains could produce perithecia and ascospores as normally as the wild-type PH-1 strain (Figure 3D), suggesting that FgRab1 is dispensable for the sexual reproduction of F. graminearum.

\subsection{FgRab1 Localizes to the Golgi, ER and Spitzenkörper}

To investigate the subcellular localization of FgRab1, we transformed GFP-FgRab1 with Lifeact-RFP, FgKar2-mCherry and FgKex2-mCherry into the protoplasts of PH-1. As shown in Figure 4, GFP-FgRab1 partially co-localized with FgKar2-mCherry, FgKex2mCherry and Lifeact-RFP in the hypha of F. graminearum. This suggests that FgRab1 is distributed around the Golgi, ER and Spitzenkörper in F. graminearum.

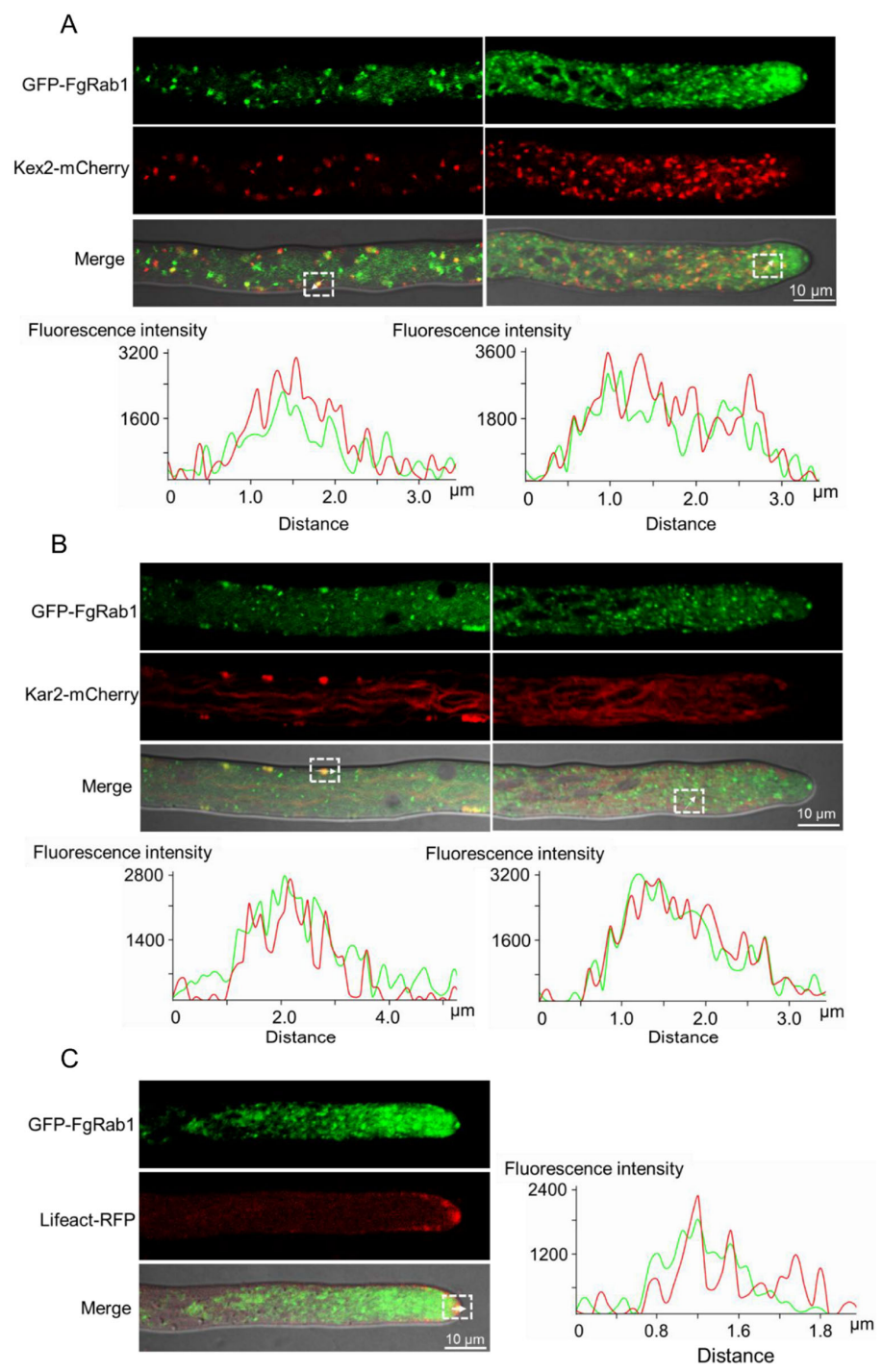

Figure 4. Subcellular localization of FgRab1. (A) GFP-FgRab1 co-localizes with the trans-Golgi marker Kex2-mCherry (marked by white arrows). A line scan graph was generated at the indicated position (arrow) to show the relative localization of GFP-FgRab1 (green) and Kex2-mCherry (red). (B) GFPFgRab1 and Kar2-mCherry co-localize to the endoplasmic reticulum (ER) (marked by white arrows). A line scan graph was generated at the indicated position (arrow) to show the relative localization of GFP-FgRab1 (green) and Kar2-mCherry (red). (C) GFP-FgRab1 localizes to the Spitzenkörper (Spk) (marked by white arrows). A line scan graph was generated at the indicated position (arrow) to show the relative localization of GFP-FgRab1 (green) and Lifeact-RFP (red). 


\subsection{FgRab1 Is Required for Vesicle Trafficking and Fusion Process in F. graminearum}

In S. cerevisiae, Rab1/Ypt1 is mainly located in the Golgi and Spitzenkörper, and it plays a role in several transport pathways. To study the role of the FgRab1 protein in the endocytosis of F. graminearum, the mycelia of the wild type and mutants were stained with FM4-64 dye [41]. Within 1 min, obvious fluorescence could be observed on the plasma membranes of all the strains. After $15 \mathrm{~min}$, a few red dots (FM4-64-labeled vesicles) appeared inside the three strains, indicating normal endocytosis, but at this time, a large amount of FM4-64 remained in the membrane on the surface of the mycelia. At $45 \mathrm{~min}$ post-staining, it was found that a large part of the FM4-64 had been internalized into the cell, and FM4-64 was particularly detected on the vacuolar membrane in PH-1 and Fgrab1CA strains, but only some tiny, fragmented vesicles were observed in the Fgrab1DN strain (Figure 5A, B).
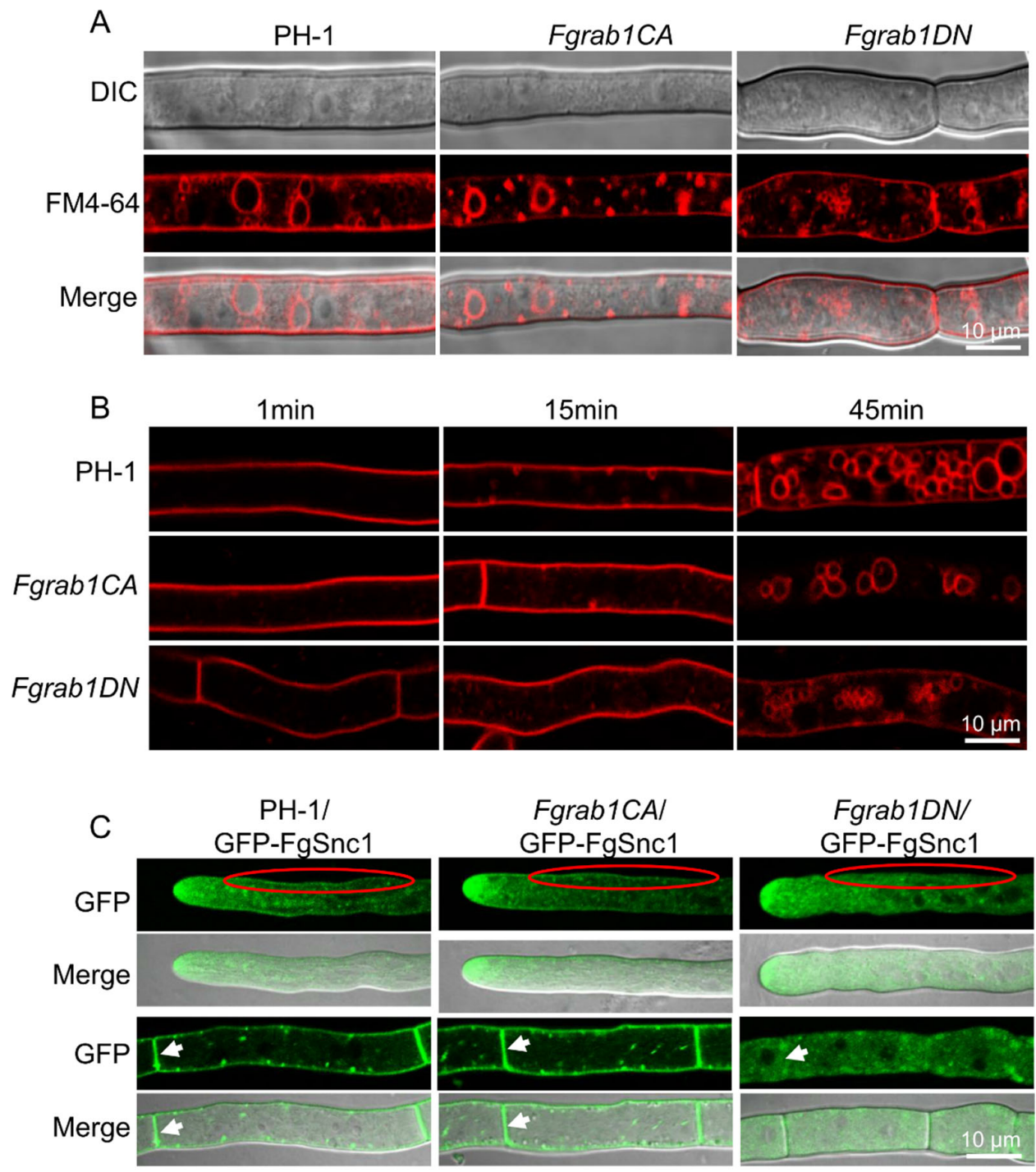

Figure 5. FgRab1 inactivation disrupts the transport of FgSnc1 to the plasma membrane and the fusion of vesicles with target membranes in F. graminearum. (A,B) FgRab1 is necessary for membrane fusion. (C) FgRab1 is required for the transport of FgSnc1 to the plasma membrane and septum. Red circles show the plasma membrane localization of GFP-FgSnc1, and white arrows show the septum localization of GFP-FgSnc1, bar $=10 \mu \mathrm{m}$.

To understand the influence of FgRab1 on vesicle transport processes, GFP-FgSnc1 was constructed and transformed into the protoplasts of PH-1, Fgrab1CA and Fgrab1DN 
strains. The localization of GFP-FgSnc1 was observed by confocal microscopy. As shown in Figure 5C, GFP-FgSnc1 localizes to the plasma membrane and concentrates at the Spitzenkörper in the growing hyphal cells of PH-1 and Fgrab1CA. However, in the Fgrab1DN strain, the plasma membrane and septum localization of this protein cannot be observed; instead, the GFP fluorescence is dispersed in the cytoplasm, though its localization to the hyphal tip was still present. These results suggest that the inactivation of FgRab1 affects the secretion of FgSnc1 from the Golgi to the plasma membrane and septum.

\subsection{FgRab1 Is Required for Pathogenicity}

To investigate the effects of Fgrab1CA and Fgrab1DN on the pathogenicity of the fungus, the mutants and the $\mathrm{PH}-1$ control were inoculated on flowering wheat heads under moist conditions for 14 days. As shown in Figure 6A, the FBH symptoms due to Fgrab1DN infection on wheat heads were significantly lower than those observed due to PH-1 and Fgrab1CA infections. These results indicate that FgRab1 is required for normal pathogenicity of F. graminearum. Furthermore, infection assays on wheat coleoptiles yielded similar results (Figure 6B). Taken together, our data demonstrate that FgRab1 is important for F. graminearum virulence.

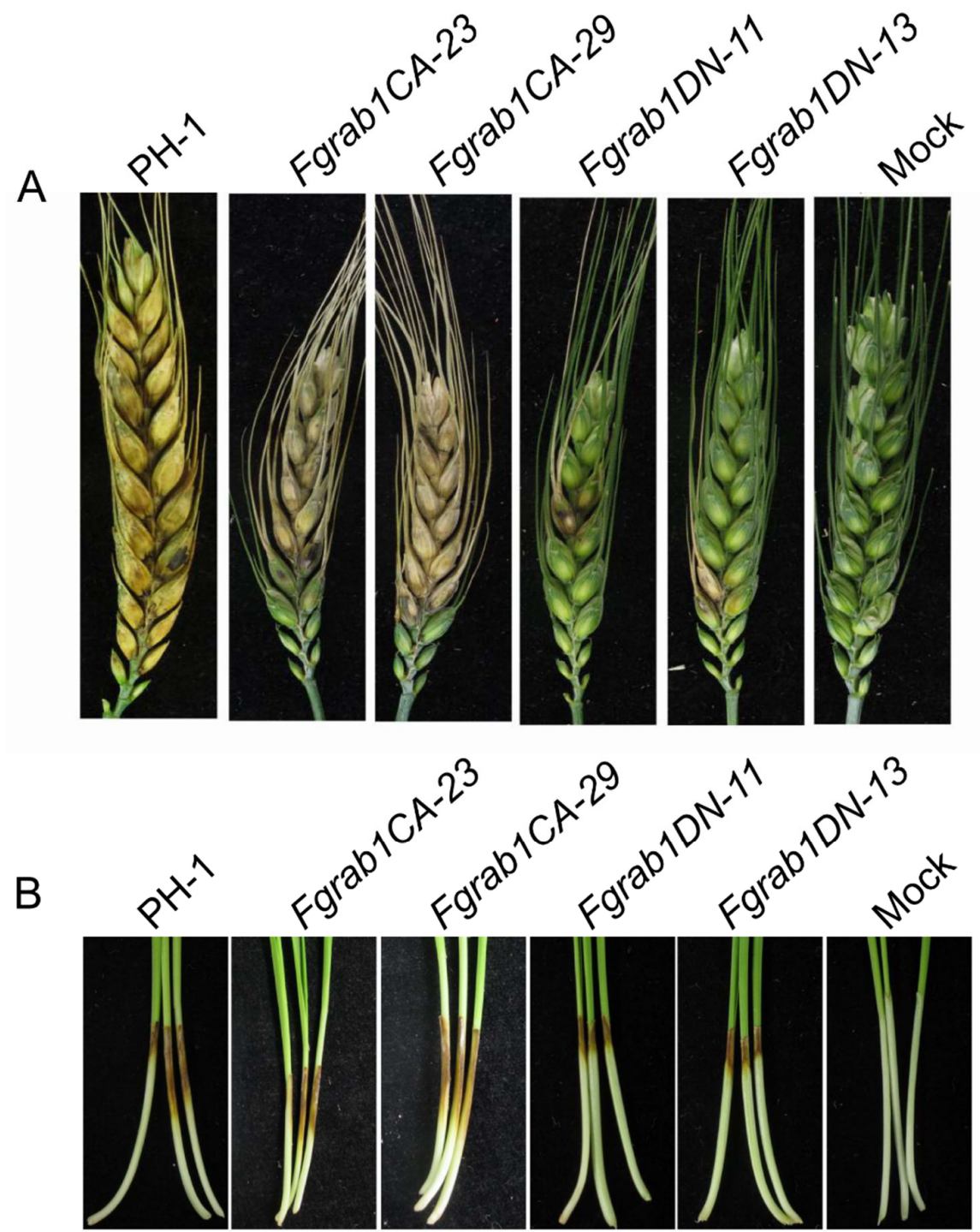

Figure 6. FgRab1 critically contributes to the pathogenicity of F. graminearum. (A) Pathogenicity of PH-1, Fgrab1CA and Fgrab1DN strains on flowering wheat heads. (B) Pathogenicity of PH-1, Fgrab1CA, Fgrab1DN strains on wheat coleoptiles. 


\subsection{Inactivation of FgRab1 Prevents Autophagy in F. graminearum}

Autophagy is a highly important and conserved intracellular process for the degradation and recycling of proteins and damaged organelles in eukaryotic organisms. GFPFgAtg8 is widely used as a marker for reflecting the level of autophagy in numerous studies [39,46-48]. To investigate whether FgRab1 is involved in autophagy in F. graminearum, we transformed GFP-FgAtg8 into the protoplasts of the wild-type PH-1, Fgrab1CA and Fgrab1DN strains. We stained the transformed strains with the vacuole marker CMAC (7-amino-4-chloromethylcoumarin) and subjected the strains to confocal microscopy. We found that GFP-FgAtg8 localized to the cytosol in all the strains, forming punctate structures within the cytosol under nutrient-rich conditions (CM medium) (Figure 7A). Upon the induction of autophagy (growth of the strains on nutrient-deficient MM media for 8 $\mathrm{h}$ in the presence of $2 \mathrm{mM}$ PMSF), more spots of GFP-FgAtg8 signals were observed in the vacuoles of PH-1 and Fgrab1CA mycelia, while the signals remained diffused within the cytosol in the Fgrab1DN strain (Figure 7B). This simply indicates that autophagy was prevented in the Fgrab1DN strain. These results indicate that FgRab1 is critically involved in autophagy in F. graminearum.

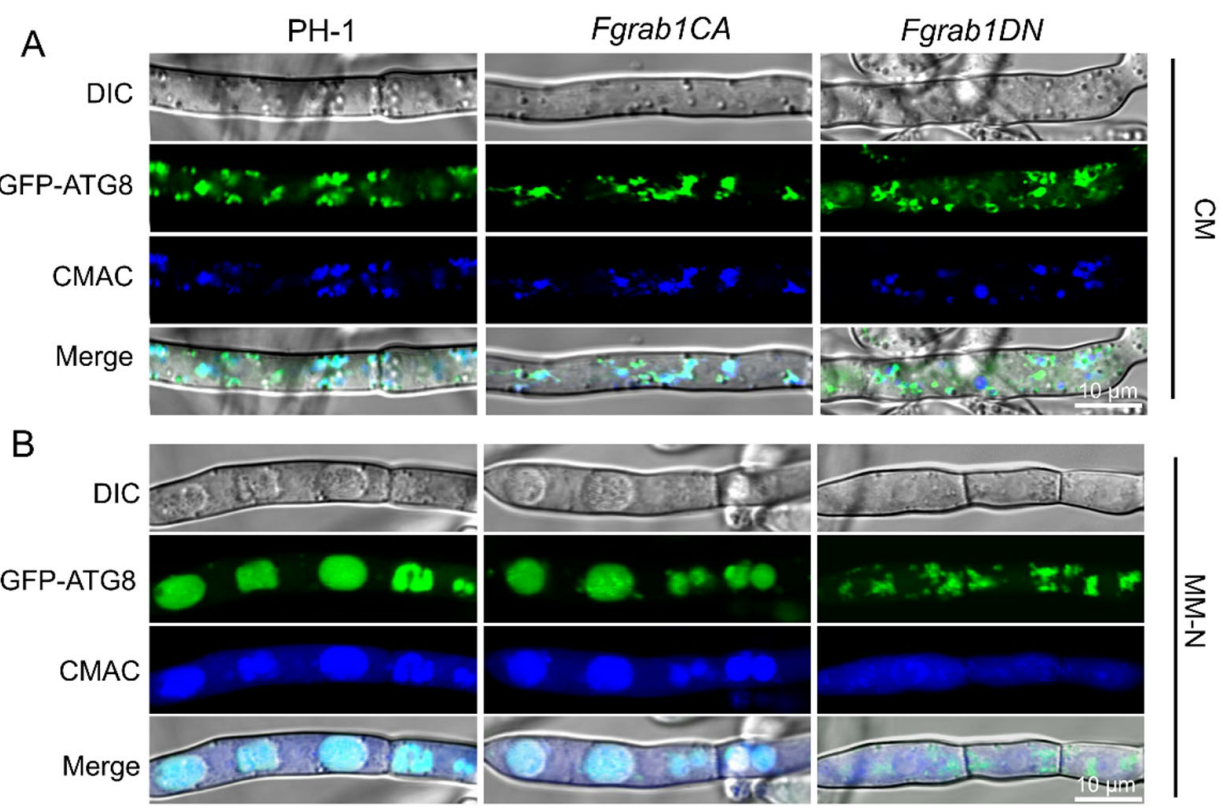

Figure 7. FgRab1 is required for autophagosome formation and autophagy in F. graminearum. Localization of GFP-FgAtg8 in PH-1, Fgrab1CA and Fgrab1DN strains in CM (A) or MM-N media (B). PH-1, Fgrab1CA and Fgrab1DN strains expressing GFP-FgAtg8 were grown in liquid CM medium at $28{ }^{\circ} \mathrm{C}$ for $16 \mathrm{~h}$ and then shifted to liquid MM-N medium containing $2 \mathrm{mM}$ PMSF for $8 \mathrm{~h}$ to induce autophagy. Mycelia were stained with CMAC and examined under a confocal microscope. Bar $=10 \mu \mathrm{m}$.

\section{Discussion}

Rabs, a subfamily of the Ras superfamily of small GTPases, are highly conserved in eukaryotic cells, which function as "molecular switches" between GTP- and GDP-bound states through interaction with two regulatory proteins, guanine nucleotide exchange factor (GEF) and GTPase-activating protein (GAP) [2,49]. Rab1 is a member of the Rab GTPase family, which is known to regulate cargo transport from the ER to the Golgi and intra-Golgi through different effectors, and it plays an essential role in the secretory pathway [50-52]. The intact $Y P T 1$ gene has been shown to be essential for spore germination and the vegetative growth of yeast cells [22]. However, the biological functions of Rab1 in the phytopathogen are still largely unknown. In mice, Rab1 has GTP-binding sites of Ser22 (S) (preferential binding) and asparagine (N) (121) (low affinity) and glutamine (Q) with GDP-binding site 67 [53]. In this study, we found that the corresponding GTP-binding 
site of FgRab1 contains serine $22(\mathrm{~S})$ and asparagine $121(\mathrm{~N})$, while the GDP-binding site contains glutamine $67(\mathrm{Q})$. Here, we used point mutation strategy to modify the active site of the FgRab1 protein, and we showed that FgRab1 is required for vegetative growth and pathogenicity in F. graminearum. Furthermore, we found that FgRab1 plays a crucial role in the secretory process from the Golgi to the plasma membrane and that it determines the effectiveness of vesicle fusion, as well as cell wall integrity. Furthermore, disrupting the functions of FgRab1 causes severe phenotypic defects, including fungal pathogenicity.

Rab1 is a key regulator of ER-to-Golgi transport, where the active Rab proteins are localized to the membranes of the endoplasmic reticulum (ER) and the Golgi apparatus [50]. In our study, we found that GFP-FgRab1 was mainly localized to the Golgi (Figure 4A), some to the ER (Figure 4B) and a small amount to the Spitzenkörper (Figure 4C). Snc1 is a $\mathrm{v}$-SNARE protein that mediates the fusion of trans-Golgi network (TGN)-derived exocytic vesicles with the plasma membrane in budding yeast; the protein is also endocytosed from the cell surface and trafficked back to the TGN, where it can be repackaged into nascent secretory vesicles to facilitate another round of transport [54]. In our previous study, we demonstrated that FgGyp1, a GAP of FgRab1, is required for the FgSnc1-mediated fusion of secretory vesicles from the Golgi with the plasma membrane [42]. In wild-type PH-1, GFPFgSnc1 is localized to the cytoplasm, Spitzenkörper, plasma membrane and septum $[41,55]$. However, in the present study, the fluorescence signal of FgSnc1 could not be observed at both the plasma membrane and septum of the Fgrab1DN strain, suggesting that the inactivation of FgRab1 affected the trafficking of FgSnc1 from the Golgi to the plasma membrane and septum. Taken together, our results indicated that the FgGyp1-FgRab1 cascade regulates the FgSnc1-mediated fusion of secretory vesicles from the Golgi with the plasma membrane.

In Drosophila, omelette (omt) is the orthologue of human Rab1. Golgi stacks appear "collapsed" in omt mutant cells, with abnormal Golgi complexes comprising fragmented cisternae and a few small stacks [52]. Moreover, in HeLa cells, an increase in Rab1b levels induces changes in Golgi size and gene expression, where the inhibition of Rab1 affects the stability of the Golgi apparatus structure, leading to the dispersal of the Golgi in the cytoplasm [56,57]. Therefore, we speculated that the inactivation of Rab1 in F. graminearum may affect the stability of the Golgi, which, in turn, could have been the reason why we observed diffused distribution of FgSnc1 in the cytoplasm, which affects the transport of FgSnc1 to the plasma membrane. It was reported in another study that inhibiting the function of Rab1 through the expression of the dominant-negative construct Rab1b N121I by siRNA transfection or overexpression of its GAP caused fragmentation of the Golgi [56]. Rab1 mediates the docking of ER-derived vesicles with the cis-Golgi compartment, where the knockdown of Rab1b alters vacuole growth, at least in part, by changing its fusogenic capacity with endocytic compartments [58]. To verify whether FgRab1 affects vesicle fusion in F. graminearum, we stained the mycelia of the wild-type PH-1, Fgrab1CA and Fgrab1DN strains with FM4-64, and we found that almost 90\% of the mycelia from the Fgrab1DN strain could not form large vacuoles, and the vacuole pieces observed in the cytoplasm showed fragmentation (Figure 5C). This result suggests that the inactivation of FgRab1 affects the vesicle fusion process, leading to vacuolar fragmentation.

Polarized growth is fundamental for optimal survival, which requires a perfect coordination among the major cellular processes, such as cytoskeletal organization, secretion and endocytosis, which have to be controlled by the cell integrity pathway and regulated by the cell cycle [59]. As shown in our results, FgRab1 exhibited an obvious defect in endocytosis from the cell surface as well as trafficking back to the TGN, which further results in defects in vacuolar transport. In addition, we found that inactivating FgRab1 led to abnormal cell wall thickness, which affected the corresponding growth process. We speculated that FgRab1 may play an important role in the formation of the cell wall.

Autophagy is a highly important and conserved intracellular process for the degradation and recycling of subcellular materials in eukaryotes, and it is critical for vesicle formation, transport, tethering and fusion; hence, it is a strong determinant of fungal 
survival, reproduction and infection $[47,60,61]$. Autophagy plays a pivotal role in supplying nutrients to non-assimilating structures necessary for growth, and it is important for plant colonization in F. graminearum [47]. As vesicle-trafficking proteins, many Rab GTPases regulate various steps of autophagy. Rab1, Rab5, Rab7, Rab8A, Rab8B, Rab9, Rab11, Rab23, Rab24, Rab25, Rab32 and Rab33B are all essential for autophagy [60]. Ypt1 and its GEF TRAPPIII have been implicated in autophagy [62]. It has been reported that Gyp1, Gyp5 and Gyp8 function as the GAP of Ypt1 [42,62,63]. In yeast, Gyp1 has not only been proposed to negatively regulate Ypt1 at the Golgi but also acts as Atg8's interacting partner for selective autophagy [62]. Rab1/Ypt1 is essential for autophagosome formation, and Trs85, a subunit of TRAPP complex III (the GEF for Ypt1), functions as a key player in channeling Ypt1 GEF and Ypt1 to the phagophore assembly site (PAS), where the key proteins are involved in autophagosome formation [64]. In this study, live-cell imaging showed abnormal autophagosomes in the Fgrab1DN strain during nitrogen starvation conditions, suggesting that autophagy was disrupted in Fgrab1DN. These results showed that FgRab1 plays an important role in autophagy.

In summary, FgRab1 is found herein to be important for pathogenicity in F. graminearum, and inactivation of the protein perturbs the fungal vegetative growth, autophagy and vesicle fusion with target membranes.

\section{Materials and Methods}

\subsection{Fungal Strains and Culture Conditions}

F. graminearum PH-1 (Taxonomy ID: 5518) was used as the wild-type strain and as a background for generating all the gene deletion mutants (Table S1). Fungal strains were cultured at $28{ }^{\circ} \mathrm{C}$ on complete medium (CM), which contained $6 \mathrm{~g} / \mathrm{L}$ yeast extract, $6 \mathrm{~g} / \mathrm{L}$ casamino acid, $10 \mathrm{~g} / \mathrm{L}$ sucrose and $20 \mathrm{~g} / \mathrm{L}$ agar (for solid medium) for mycelial growth. Carboxymethyl cellulose liquid medium (CMC) $\left(1 \mathrm{~g} / \mathrm{L} \mathrm{NH}_{4} \mathrm{NO}_{3}, 1 \mathrm{~g} / \mathrm{L}\right.$ yeast extract, $1 \mathrm{~g} / \mathrm{L}$ $\mathrm{KH}_{2} \mathrm{PO}_{4}, 0.5 \mathrm{~g} / \mathrm{L} \mathrm{MgSO} \cdot 7 \mathrm{H}_{2} \mathrm{O}, 15 \mathrm{~g} / \mathrm{L}$ carboxymethyl cellulose) was used for conidiation assays. Liquid trichothecene biosynthesis induction (TBI) medium $\left(0.01 \mathrm{~g} / \mathrm{L} \mathrm{FeSO} \cdot 7 \mathrm{H}_{2} \mathrm{O}\right.$, $0.05 \mathrm{~g} / \mathrm{L} \mathrm{MgSO}_{4} \cdot 7 \mathrm{H}_{2} \mathrm{O}, 0.5 \mathrm{~g} / \mathrm{L} \mathrm{KCl}, 1 \mathrm{~g} / \mathrm{L} \mathrm{KH}_{2} \mathrm{PO}_{4}, 0.0871 \mathrm{~g} / \mathrm{L}$ arginine, $30 \mathrm{~g} / \mathrm{L}$ sucrose, $200 \mu \mathrm{L} / \mathrm{L}$ trace elements, $\mathrm{pH}=6.5$ ) was used for trichothecene production analysis [9]. Carrot agar medium (400 g/L fresh carrot, $20 \mathrm{~g} / \mathrm{L}$ agar) was used for inducing perithecia and ascospore formation. A $1000 \times$ trace element solution $\left(22 \mathrm{~g} / \mathrm{L} \mathrm{ZnSO} 4 \cdot 7 \mathrm{H}_{2} \mathrm{O}, 11 \mathrm{~g} / \mathrm{L}\right.$ $\mathrm{H}_{3} \mathrm{BO}_{3}, 5 \mathrm{~g} / \mathrm{L} \mathrm{MnCl}_{2} \cdot 4 \mathrm{H}_{2} \mathrm{O}, 5 \mathrm{~g} / \mathrm{L} \mathrm{FeSO}_{4} \cdot 7 \mathrm{H}_{2} \mathrm{O}, 1.7 \mathrm{~g} / \mathrm{L} \mathrm{CoCl}_{2} \cdot 6 \mathrm{H}_{2} \mathrm{O}, 1.6 \mathrm{~g} / \mathrm{L} \mathrm{CuSO} 4 \cdot 5 \mathrm{H}_{2} \mathrm{O}$, $1.5 \mathrm{~g} / \mathrm{L} \mathrm{Na}_{2} \mathrm{MoO}_{4} \cdot 5 \mathrm{H}_{2} \mathrm{O}, 50 \mathrm{~g} / \mathrm{L}$ EDTA $4 \mathrm{Na}$ ) and $1000 \times$ vitamin solution $(0.1 \mathrm{~g} / \mathrm{L}$ biotin, $0.1 \mathrm{~g} / \mathrm{L}$ pyridoxin, $0.1 \mathrm{~g} / \mathrm{L}$ thiamine, $0.1 \mathrm{~g} / \mathrm{L}$ riboflavin, $0.1 \mathrm{~g} / \mathrm{L}$ p-aminobenzoic acid, $0.1 \mathrm{~g} / \mathrm{L}$ nicotinic acid) were used for nitrogen-deficient minimal medium (MM-N, $0.52 \mathrm{~g} / \mathrm{L}$ $\mathrm{KCl}, 0.312 \mathrm{~g} / \mathrm{L} \mathrm{MgSO} 4 \cdot 7 \mathrm{H}_{2} \mathrm{O}, 1.52 \mathrm{~g} / \mathrm{L} \mathrm{KH}_{2} \mathrm{PO}_{4}, 1 \mathrm{~mL} / \mathrm{L} 1000 \times$ trace element solution, $1 \mathrm{~mL} / \mathrm{L} 1000 \times$ vitamin solution). RNA was extracted from fresh mycelia harvested from $100 \mathrm{~mL}$ liquid $\mathrm{CM}$ cultured at $28^{\circ} \mathrm{C}$ with constant shaking at $110 \mathrm{rpm}$ for 3 days. The fresh mycelia were ground in liquid nitrogen into powder, and the total RNA was extracted using Eastep $^{\text {TM }}$ Total RNA extraction Kit (Promega, Beijing). Each experiment was repeated three times.

\subsection{Construction of Constitutively Active and Dominant-Negative Mutants}

To generate dominant-negative and constitutively active $F g R A B 1$ mutants, we first used the primer pairs FgRab1DN1F/FgRab1DN1R and FgRab1DN2F/FgRab1DN2R, FgRab1DN1F/FgRabCA1R and FgRab1CA2F/FgRab1DN2R (Table S2) to amplify FgRAB1 DN1, DN2, CA1 and CA2, respectively, by PCR from the cDNA of PH-1, and the products were further subjected to splicing for overlap extension (SOE)-PCR to obtain the mutated constructs as previously reported [9]. The latter products were then cloned into Bam $\mathrm{H} \mathrm{I}$ and Not I plasmids, downstream of the RP27 promoter on the pTE11-vector and verified by sequencing. 


\subsection{Quantitative Real-Time PCR}

For qRT-PCR, the Fgrab1DN, Fgrab1CA and PH-1 strains were inoculated in liquid $\mathrm{CM}$ medium and incubated at $28{ }^{\circ} \mathrm{C}$ for $16 \mathrm{~h}$. Total RNA was isolated from mycelia using Eastep ${ }^{\mathrm{TM}}$ Total RNA extraction Kit (Promega, Beijing, China), and first-strand cDNA was synthesized using M-MLV (Moloney murine leukemia virus) reverse transcriptase (HiScript III RT SuperMix for qPCR (+gDNA wiper), Vazyme, Nanjing, China). Relative transcription levels were quantified using QuantiTect SYBRgreen PCR Master Mix (Takara, Kusatsu City, Japan), using the primer pairs (Supplementary Table S2). The tubulin beta chain gene (FGSG_09530) was used as the endogenous reference gene, and the data of relative quantification were calculated using the $2^{-\Delta \Delta C T}$ method [65]. All experiments and qRT-PCR assays were repeated three times.

\subsection{Asexual and Sexual Reproduction Assays}

Mycelial agar blocks ( $5 \mathrm{~mm}$ in diameter) were inoculated into CMC liquid medium to assay asexual reproduction [9]. The number of conidia was determined 3 days after incubation at $28^{\circ} \mathrm{C}$, using a hemacytometer (QIUJING, Shanghai, China) under an Olympus BX53F microscope (Olympus, Tokyo, Japan). To induce sexual reproduction, mycelial agar blocks were placed on carrot agar and incubated at $28^{\circ} \mathrm{C}$ for $5-7$ days, after which aerial hyphae were removed, and the plates were pressed down gently with $1 \mathrm{~mL}$ of $2.5 \%$ sterile Tween 60 (Macklin, Shanghai, China). All of the sexual reproduction-induced cultures were incubated at $28{ }^{\circ} \mathrm{C}$ under black light (F20T8/BLB, wavelength: $365 \mathrm{~nm}$, Danqi, Shanghai, China). The perithecia formed were photographed and recorded. Each experiment was independently repeated three times.

\subsection{Pathogenicity Assays}

Nearly the same quantities of fresh mycelia were inoculated into the center of flowering wheat heads, after which, the wheat heads were sprayed with sterile distilled water and covered with transparent polythene bags. After 7 days, the bags were removed, and after another 7 days, the wheat heads were cut off and photographed [9]. For conidial samples, $2 \mu \mathrm{L}$ of $100 \times 10^{4}$ cells $/ \mathrm{mL}$ conidial suspension was inoculated in each coleoptile, and the observed symptoms were recorded after 7 days of inoculation.

\subsection{Autophagy Assay}

Autophagy was assayed by determining the expression of FgAtg8. We transformed the GFP-FgAtg8 construct into the PH-1, Fgrab1CA and Fgrab1DN strains. The transformants were cultured in liquid $\mathrm{CMC}$ for 3 days to obtain their respective conidia. The conidia were harvested and transferred into fresh liquid $\mathrm{CM}$ cultures and further incubated for $16 \mathrm{~h}$ at $28^{\circ} \mathrm{C}$, with shaking at $180 \mathrm{rpm}$. The conidia were then transferred into "starvation media", that is, nitrogen-deficient minimal media (MM-N) containing $2 \mathrm{mM}$ phenylmethylsulfonyl fluoride (PMSF), and cultured for $8 \mathrm{~h}$ at $28{ }^{\circ} \mathrm{C}, 150 \mathrm{rpm}$. Mycelia were stained with 7-amino-4-chloromethylcoumarin (CMAC) for $30 \mathrm{~min}$ and observed under fluorescence confocal microscope.

\subsection{Live-Cell Imaging of F. graminearum}

Confocal microscopy was used for time-lapse or live-cell fluorescence imaging using a Nikon A1R laser scanning confocal microscope system (Nikon, Tokyo, Japan). Alternatively, an Olympus BX51 microscope (Olympus, Tokyo, Japan) was used for conventional epifluorescence and differential interference contrast (DIC). Elapsed time is indicated in seconds. We used $405 \mathrm{~nm}$ light (Em. 452/45 nm) for Calcofluor white and CMAC excitations. GFP excitation was performed using $488 \mathrm{~nm}$ light (Em. 525/40 nm), and FM4-64 and mCherry excitations were performed using $561 \mathrm{~nm}$ light (Em. 607/36 nm) [9]. 


\subsection{Statistical Analysis}

GraphPad Prism 8 (Scientific Software, San Diego, CA, USA) was used to calculate the standard error of the mean (sem) for all values shown. $p$ values were calculated with a two-tailed Student's $t$-test using Microsoft Excel (Microsoft, Redmond, WA, USA).

Supplementary Materials: The following supporting information can be downloaded at: https:/ / www.mdpi.com/article/10.3390/ijms23020895/s1.

Author Contributions: Y.Y., J.L., H.Z. and J.Z. planned and designed this experiment; Y.Y. conducted the research, methodology and writing and editing; M.Z., J.L., C.Y. and X.C. performed the experiments; Y.S.A., Z.W., W.Z., H.Z. and J.Z. contributed to the critical revision of the manuscript. All authors have read and agreed to the published version of the manuscript.

Funding: This research was supported by the National Natural Science Foundation of China (31870136, 31670142) and the Natural Science Foundation of Fujian Province (2020J06047). The authors declare no conflict of interest.

Institutional Review Board Statement: Not applicable.

Informed Consent Statement: Not applicable.

Data Availability Statement: Any data or material that support the findings of this study can be made available by the corresponding author upon request.

Acknowledgments: We thank Jin-Rong Xu (Purdue University, West Lafayette, IN, USA) for providing the F. graminearum wild-type strain PH-1.

Conflicts of Interest: The authors declare no conflict of interest. The funders had no role in the design of the study; in the collection, analyses, or interpretation of data; in the writing of the manuscript; or in the decision to publish the results.

\section{References}

1. Pinar, M.; Peñalva, M.A. The fungal RABOME: RAB GTPases acting in the endocytic and exocytic pathways of Aspergillus nidulans (with excursions to other filamentous fungi). Mol. Microbiol. 2021, 116, 53-70. [CrossRef] [PubMed]

2. Mizuno-Yamasaki, E.; Rivera-Molina, F.; Novick, P. GTPase Networks in Membrane Traffic. Annu. Rev. Biochem. 2012, 81, 637-659. [CrossRef]

3. Stenmark, H. Rab GTPases as coordinators of vesicle traffic. Nat. Rev. Mol. Cell Biol. 2009, 10, 513-525. [CrossRef] [PubMed]

4. Li, G.; Marlin, M.C. Rab family of GTPases. Methods Mol. Biol. 2015, 1298, 1-15.

5. Dautt-Castro, M.; Rosendo-Vargas, M.; Casas-Flores, S. The Small GTPases in Fungal Signaling Conservation and Function. Cells 2021, 10, 1039. [CrossRef] [PubMed]

6. Bourne, H.R.; Sanders, D.A.; McCormick, F. The GTPase superfamily: Conserved structure and molecular mechanism. Nature 1991, 349, 117-127. [CrossRef]

7. Pereira-Leal, J.B. The Ypt/Rab family and the evolution of trafficking in fungi. Traffic 2008, 9, 27-38. [CrossRef] [PubMed]

8. Liu, J.; Lei, M.; Zhou, Y.; Chen, F. A Comprehensive Analysis of the Small GTPases Ypt7 Involved in the Regulation of Fungal Development and Secondary Metabolism in Monascus ruber M7. Front. Microbiol. 2019, 10, 452. [CrossRef]

9. Zheng, H.; Zheng, W.; Wu, C.; Yang, J.; Xi, Y.; Xie, Q.; Zhao, X.; Deng, X.; Lu, G.; Li, G.; et al. Rab GTPases are essential for membrane trafficking-dependent growth and pathogenicity in Fusarium graminearum. Environ. Microbiol. 2015, 17, 4580-4599. [CrossRef]

10. Irieda, H.; Maeda, H.; Akiyama, K.; Hagiwara, A.; Saitoh, H.; Uemura, A.; Terauchi, R.; Takano, Y. Colletotrichum orbiculare Secretes Virulence Effectors to a Biotrophic Interface at the Primary Hyphal Neck via Exocytosis Coupled with SEC22-Mediated Traffic. Plant Cell 2014, 26, 2265-2281. [CrossRef]

11. Bielska, E.; Higuchi, Y.; Schuster, M.; Steinberg, N.; Kilaru, S.; Talbot, N.J.; Steinberg, G. Long-distance endosome trafficking drives fungal effector production during plant infection. Nat. Commun. 2014, 5, 5097. [CrossRef]

12. Zhang, Z.Q.; Qin, G.Z.; Li, B.Q.; Tian, S.P. Knocking Out Bcsas1 in Botrytis cinerea Impacts Growth, Development, and Secretion of Extracellular Proteins, Which Decreases Virulence. Mol. Plant Microbe Interact. 2014, 27, 590-600. [CrossRef]

13. Yan, H.; Huang, J.; Zhang, H.; Shim, W.B. A Rab GTPase protein FvSec4 is necessary for fumonisin B1 biosynthesis and virulence in Fusarium verticillioides. Curr. Genet. 2020, 66, 205-216. [CrossRef]

14. Yang, C.D.; Dang, X.; Zheng, H.W.; Chen, X.F.; Lin, X.L.; Zhang, D.M.; Abubakar, Y.S.; Chen, X.; Lu, G.; Wang, Z.; et al. Two Rab5 Homologs Are Essential for the Development and Pathogenicity of the Rice Blast Fungus Magnaporthe oryzae. Front. Plant. Sci. 2017, 8, 620. [CrossRef] 
15. Qi, Y.; Marlin, M.C.; Liang, Z.; Berry, W.L.; Janknecht, R.; Zhou, J.; Wang, Z.; Lu, G.; Li, G. Distinct Biochemical and Functional Properties of Two Rab5 Homologs from the Rice Blast Fungus Magnaporthe oryzae. J. Biol. Chem. 2014, 289, 28299-282309. [CrossRef] [PubMed]

16. Liu, X.H.; Chen, S.M.; Gao, H.M.; Ning, G.A.; Shi, H.B.; Wang, Y.; Dong, B.; Qi, Y.Y.; Zhang, D.M.; Lu, G.D.; et al. The small GTPase MoYpt7 is required for membrane fusion in autophagy and pathogenicity of Magnaporthe oryzae. Environ. Microbiol. 2015, 17, 4495-4510. [CrossRef] [PubMed]

17. Wu, C.; Lin, Y.; Zheng, H.; Abubakar, Y.S.; Peng, M.; Li, J.; Yu, Z.; Wang, Z.; Naqvi, N.I.; Li, G.; et al. The retromer CSC subcomplex is recruited by MoYpt7 and sequentially sorted by MoVps17 for effective conidiation and pathogenicity of the rice blast fungus. Mol. Plant Pathol. 2021, 22, 284-298. [CrossRef]

18. Zheng, H.; Chen, S.; Chen, X.; Liu, S.; Dang, X.; Yang, C.; Giraldo, M.C.; Oliveira-Garcia, E.; Zhou, J.; Wang, Z.; et al. The Small GTPase MoSec4 Is Involved in Vegetative Development and Pathogenicity by Regulating the Extracellular Protein Secretion in Magnaporthe oryzae. Front. Plant. Sci. 2016, 7, 1458. [CrossRef]

19. Siriputthaiwan, P.; Jauneau, A.; Herbert, C.; Garcin, D.; Dumas, B. Functional analysis of CLPT1, a Rab/GTPase required for protein secretion and pathogenesis in the plant fungal pathogen Colletotrichum lindemuthianum. J. Cell Sci. 2005, 118, 323-329. [CrossRef] [PubMed]

20. Schmitt, H.D.; Puzicha, M.; Gallwitz, D. Study of a temperature-sensitive mutant of the ras-related YPT1 gene product in yeast suggests a role in the regulation of intracellular calcium. Cell 1988, 53, 635-647. [CrossRef]

21. Schmitt, H.D.; Wagner, P.; Pfaff, E.; Gallwitz, D. The ras-related YPT1 gene product in yeast: A GTP-binding protein that might be involved in microtubule organization. Cell 1986, 47, 401-412. [CrossRef]

22. Segev, N.; Botstein, D. The ras-like yeast YPT1 gene is itself essential for growth, sporulation, and starvation response Mol. Cell. Biol. 1987, 7, 2367-2377.

23. Bacon, R.A.; Salminen, A.; Ruohola, H.; Novick, P.; Ferro-Novick, S. The GTP-binding protein Ypt1 is required for transport in vitro: The Golgi apparatus is defective in ypt1 mutants. J. Cell Biol. 1989, 109, 1015-1022. [CrossRef]

24. Miyake, S.; Yamamoto, M. Identification of ras-related, YPT family genes in Schizosaccharomyces pombe. EMBO J. 1990, 9, 1417-1422. [CrossRef]

25. Lee, S.A.; Mao, Y.; Zhang, Z.; Wong, B. Overexpression of a dominant-negative allele of YPT1 inhibits growth and aspartyl protease secretion in Candida albicans. Microbiology 2001, 147, 1961-1970. [CrossRef] [PubMed]

26. Pind, S.N.; Nuoffer, C.; McCaffery, J.M.; Plutner, H.; Davidson, H.W.; Farquhar, M.G.; Balch, W.E. Rab1 and Ca2+ are required for the fusion of carrier vesicles mediating endoplasmic reticulum to Golgi transport. J. Cell Biol. 1994, 125, 239-252. [CrossRef] [PubMed]

27. Bushnell, W.; Hazen, B.; Pritsch, C.; Leonard, K. Histology and physiology of Fusarium head blight. In Fusarium Head Blight of Wheat and Barley; Leonard, K.J., Bushnell, W.R., Eds.; APS Press: St. Paul, MN, USA, 2003; pp. 44-83.

28. Bai, G.; Shaner, G. Management and resistance in wheat and barley to fusarium head blight. Annu. Rev. Phytopathol. 2004, 42, 135-161. [CrossRef] [PubMed]

29. Gardiner, D.M.; Rusu, A.; Barrett, L.; Hunter, G.C.; Kazan, K. Can natural gene drives be part of future fungal pathogen control strategies in plants? New Phytol. 2020, 228, 1431-1439. [CrossRef]

30. Lofgren, L.A.; LeBlanc, N.R.; Certano, A.K.; Nachtigall, J.; LaBine, K.M.; Riddle, J.; Broz, K.; Dong, Y.; Bethan, B.; Kafer, C.W.; et al. Fusarium graminearum: Pathogen or endophyte of North American grasses? New Phytol. 2018, 217, 1203-1212. [CrossRef]

31. Bönnighausen, J.; Schauer, N.; Schäfer, W.; Bormann, J. Metabolic profiling of wheat rachis node infection by Fusarium graminearum-Decoding deoxynivalenol-dependent susceptibility. New Phytol. 2019, 221, 459-469. [CrossRef] [PubMed]

32. Boenisch, M.J.; Schäfer, W. Fusarium graminearum forms mycotoxin producing infection structures on wheat. BMC Plant Biol. 2011, 11, 110. [CrossRef] [PubMed]

33. Zhou, S.; Zhang, Y.K.; Kremling, K.A.; Ding, Y.; Bennett, J.S.; Bae, J.S.; Kim, D.K.; Ackerman, H.H.; Kolomiets, M.V.; Schmelz, E.A.; et al. Ethylene signaling regulates natural variation in the abundance of antifungal acetylated diferuloylsucroses and Fusarium graminearum resistance in maize seedling roots. New Phytol. 2019, 221, 2096-2111. [CrossRef]

34. Boddu, J.; Cho, S.; Kruger, W.M.; Muehlbauer, G.J. Transcriptome analysis of the barley-Fusarium graminearum interaction. Mol. Plant Microbe Interact 2006, 19, 407-417. [CrossRef]

35. Yang, L.; Van der Lee, T.; Yang, X.; Yu, D.; Waalwijk, C. Fusarium populations on Chinese barley show a dramatic gradient in mycotoxin profiles. Phytopathology 2008, 98, 719-727. [CrossRef]

36. Zhang, Y.; He, J.; Jia, L.J.; Yuan, T.L.; Zhang, D.; Guo, Y.; Wang, Y.; Tang, W.H. Cellular Tracking and Gene Profiling of Fusarium graminearum during Maize Stalk Rot Disease Development Elucidates Its Strategies in Confronting Phosphorus Limitation in the Host Apoplast. PLoS Pathog. 2016, 12, e1005485. [CrossRef] [PubMed]

37. Chen, Y.; Kistler, H.C.; Ma, Z. Fusarium graminearum Trichothecene Mycotoxins: Biosynthesis, Regulation, and Management. Annu. Rev. Phytopathol. 2019, 57, 15-39. [CrossRef] [PubMed]

38. Yang, C.; Li, J.; Chen, X.; Zhang, X.; Liao, D.; Yun, Y.; Zheng, W.; Abubakar, Y.S.; Li, G.; Wang, Z.; et al. FgVps9, a Rab5 GEF, Is Critical for DON Biosynthesis and Pathogenicity in Fusarium graminearum. Front Microbiol 2020, 11, 1714. [CrossRef] [PubMed]

39. Li, Y.; Li, B.; Liu, L.; Chen, H.; Zhang, H.; Zheng, X.; Zhang, Z. FgMon1, a guanine nucleotide exchange factor of FgRab7, is important for vacuole fusion, autophagy and plant infection in Fusarium graminearum. Sci. Rep. 2015, 5, 18101. [CrossRef] 
40. Zheng, H.; Li, L.; Miao, P.; Wu, C.; Chen, X.; Yuan, M.; Fang, T.; Norvienyeku, J.; Li, G.; Zheng, W.; et al. FgSec2A, a guanine nucleotide exchange factor of FgRab8, is important for polarized growth, pathogenicity and deoxynivalenol production in Fusarium graminearum. Environ Microbiol 2018, 20, 3378-3392. [CrossRef] [PubMed]

41. Zheng, H.; Li, L.; Yu, Z.; Yuan, Y.; Zheng, Q.; Xie, Q.; Li, G.; Abubakar, Y.S.; Zhou, J.; Wang, Z.; et al. FgSpa2 recruits FgMsb3, a Rab8 GAP, to the polarisome to regulate polarized trafficking, growth and pathogenicity in Fusarium graminearum. New Phytol. 2021, 229, 1665-1683. [CrossRef]

42. Zheng, Q.; Yu, Z.; Yuan, Y.; Sun, D.; Abubakar, Y.S.; Zhou, J.; Wang, Z.; Zheng, H. The GTPase-Activating Protein FgGyp1 Is Important for Vegetative Growth, Conidiation, and Virulence and Negatively Regulates DON Biosynthesis in Fusarium graminearum. Front. Microbiol. 2021, 12, 621519. [CrossRef]

43. Pereira-Leal, J.B.; Seabra, M.C. The mammalian Rab family of small GTPases: Definition of family and subfamily sequence motifs suggests a mechanism for functional specificity in the Ras superfamily. J. Mol. Biol. 2000, 301, 1077-1087. [CrossRef] [PubMed]

44. Pereira-Leal, J.B.; Strom, M.; Godfrey, R.F.; Seabra, M.C. Structural determinants of Rab and Rab Escort Protein interaction: Rab family motifs define a conserved binding surface. Biochem. Biophys. Res. Commun. 2003, 301, 92-97. [CrossRef]

45. Ali, B.R.; Wasmeier, C.; Lamoreux, L.; Strom, M.; Seabra, M.C. Multiple regions contribute to membrane targeting of Rab GTPases. J. Cell Sci. 2004, 117, 6401-6412. [CrossRef] [PubMed]

46. Zheng, H.; Miao, P.; Lin, X.; Li, L.; Wu, C.; Chen, X.; Abubakar, Y.S.; Norvienyeku, J.; Li, G.; Zhou, J.; et al. Small GTPase Rab7-mediated FgAtg9 trafficking is essential for autophagy-dependent development and pathogenicity in Fusarium graminearum. PLoS Genet. 2018, 14, e1007546. [CrossRef]

47. Josefsen, L.; Droce, A.; Sondergaard, T.E.; Sorensen, J.L.; Bormann, J.; Schafer, W.; Giese, H.; Olsson, S. Autophagy provides nutrients for nonassimilating fungal structures and is necessary for plant colonization but not for infection in the necrotrophic plant pathogen Fusarium graminearum. Autophagy 2012, 8, 326-337. [CrossRef] [PubMed]

48. Han, X.; Chen, L.; Li, W.; Zhang, L.; Zhang, L.; Zou, S.; Liang, Y.; Yu, J.; Dong, H. Endocytic FgEde1 regulates virulence and autophagy in Fusarium graminearum. Fungal Genet. Biol. 2020, 141, 103400. [CrossRef]

49. Thomas, L.L.; Fromme, J.C. Extensive GTPase crosstalk regulates Golgi trafficking and maturation. Curr. Opin. Cell Biol. 2020, 65, 1-7. [CrossRef]

50. Yang, X.Z.; Li, X.X.; Zhang, Y.J.; Rodriguez-Rodriguez, L.; Xiang, M.Q.; Wang, H.Y.; Zheng, X.F. Rab1 in cell signaling, cancer and other diseases. Oncogene 2016, 35, 5699-5704. [CrossRef]

51. Laura, M.; Westrate, M.J.H.; Nash, M.J.; Voeltz, G.K. Vesicular and uncoated Rab1-dependent cargo carriers facilitate ER to Golgi transport. J. Cell Sci. 2020, 133, jcs239814.

52. Sechi, S.; Frappaolo, A.; Fraschini, R.; Capalbo, L.; Gottardo, M.; Belloni, G.; Glover, D.M.; Wainman, A.; Giansanti, M.G. Rab1 interacts with GOLPH3 and controls Golgi structure and contractile ring constriction during cytokinesis in Drosophila melanogaster Open Biol. 2017, 7, 160257. [CrossRef] [PubMed]

53. Thomas Weide, M.K.; Barnekow, A. Inactive and active mutants of rab1b are not tightly integrated into target membranes. Int. J. Oncol. 1999, 15, 727-736.

54. Best, J.T.; Xu, P.; McGuire, J.G.; Leahy, S.N.; Graham, T.R. Yeast synaptobrevin, Snc1, engages distinct routes of postendocytic recycling mediated by a sorting nexin, Rcy1-COPI, and retromer. Mol. Biol. Cell 2020, 31, 944-962. [CrossRef]

55. Zheng, W.; Lin, Y.; Fang, W.; Zhao, X.; Lou, Y.; Wang, G.; Zheng, H.; Liang, Q.; Abubakar, Y.S.; Olsson, S.; et al. The endosomal recycling of FgSnc1 by FgSnx41-FgSnx4 heterodimer is essential for polarized growth and pathogenicity in Fusarium graminearum. New Phytol. 2018, 219, 654-671. [CrossRef] [PubMed]

56. Romero, N.; Dumur, C.I.; Martinez, H.; Garcia, I.A.; Monetta, P.; Slavin, I.; Sampieri, L.; Koritschoner, N.; Mironov, A.A.; De Matteis, M.A.; et al. Rab1b overexpression modifies Golgi size and gene expression in HeLa cells and modulates the thyrotrophin response in thyroid cells in culture. Mol. Biol. Cell 2013, 24, 617-632. [CrossRef] [PubMed]

57. Alvarez, C.; Garcia-Mata, R.; Brandon, E.; Sztul, E. COPI recruitment is modulated by a Rab1b-dependent mechanism Mol. Biol. Cell 2003, 14, 2116-2127. [CrossRef]

58. Campoy, E.M.; Zoppino, F.C.; Colombo, M.I. The early secretory pathway contributes to the growth of the Coxiella-replicative niche. Infect. Immun. 2011, 79, 402-413. [CrossRef]

59. Pérez González, P.R.P.; Sergio, A. Rho GTPases: Regulation of cell polarity and growth in yeasts. Biochem. J. 2010, 426, 243-253. [CrossRef] [PubMed]

60. Ao, X.; Zou, L.; Wu, Y. Regulation of autophagy by the Rab GTPase network. Cell Death Differ. 2014, 21, 348-358. [CrossRef]

61. Liu, X.H.; Gao, H.M.; Xu, F.; Lu, J.P.; Devenish, R.J.; Lin, F.C. Autophagy vitalizes the pathogenicity of pathogenic fungi. Autophagy 2012, 8, 1415-1425. [CrossRef]

62. Mitter, A.L.; Schlotterhose, P.; Krick, R. Gyp1 has a dual function as Ypt1 GAP and interaction partner of Atg8 in selective autophagy. Autophagy 2019, 15, 1031-1050. [CrossRef] [PubMed]

63. Du, L.L.; Novick, P. Yeast rab GTPase-activating protein Gyp1p localizes to the Golgi apparatus and is a negative regulator of Ypt1p. Mol. Biol. Cell 2001, 12, 1215-1226. [CrossRef] [PubMed]

64. Joiner, A.M.; Phillips, B.P.; Yugandhar, K.; Sanford, E.J.; Smolka, M.B.; Yu, H.; Miller, E.A.; Fromme, J.C. Structural basis of TRAPPIII-mediated Rab1 activation. EMBO J. 2021, 40, e107607. [CrossRef]

65. Livak, K.J.; Schmittgen, T.D. Analysis of relative gene expression data using real-time quantitative PCR and the 2(-Delta Delta C(T)) Method. Methods 2001, 25, 402-408. [CrossRef] [PubMed] 